\title{
Commentary: Mechanical circulatory support for cardiac retransplantation-The debate continues
}

\author{
Francis D. Pagani, MD, PhD
}

\author{
From the Department of Cardiac Surgery, University of Michigan, Ann Arbor, Mich. \\ Disclosures: Author has nothing to disclose with regard to commercial support. \\ Received for publication Jan 23, 2019; accepted for publication Jan 23, 2019; available ahead of print March 7 , \\ 2019. \\ Address for reprints: Francis D. Pagani, MD, PhD, Otto Gago, MD Endowed Professor of Cardiac Surgery, 5161 \\ Cardiovascular Center, University of Michigan, 1500 E Medical Center Dr, Ann Arbor, MI 48109 (E-mail: \\ fpagani@umich.edu). \\ J Thorac Cardiovasc Surg 2019;158:182-3 \\ $0022-5223 / \$ 36.00$ \\ Copyright (c) 2019 by The American Association for Thoracic Surgery \\ https://doi.org/10.1016/j.jtcvs.2019.01.091
}

Cardiac transplantation is the standard therapy for treatment of refractory advanced heart failure and affords patients a median survival extending to more than 12 years in the modern era. ${ }^{1}$ A significant cause of mortality and morbidity associated with cardiac transplantation arises from failure of the cardiac allograft, which occurs from primary graft dysfunction, acute rejection, or cardiac vasculopathy. In many circumstances, acute failure of the cardiac allograft requires mechanical circulatory support (MCS) as a bridge to cardiac recovery or retransplantation.

In this issue of the Journal, Sanchez and colleagues ${ }^{2}$ report on the data from 81 patients receiving MCS for cardiac retransplantation from the United Network for Organ Sharing database and compared their outcomes with those of patients undergoing cardiac retransplantation without MCS $(\mathrm{N}=383)$. Patients were bridged with MCS with either extracorporeal membrane oxygenation $(\mathrm{n}=29$; $35.8 \%)$, total artificial heart ( $\mathrm{n}=13 ; 16.0 \%)$, or temporary or durable ventricular assist device $(\mathrm{n}=39 ; 48.1 \%)$. Twelve $(14.8 \%)$ were supported with a second device before retransplant. Of the MCS group, 39\% underwent retransplantation because of primary graft dysfunction or acute rejection, versus $6 \%$ of the non-MCS group, and $30 \%$ of the MCS cohort were listed for retransplantation for failure of the allograft as a result of allograft vasculopathy, compared with $59 \%$ of the non-MCS group. The 30-day mortality was significantly higher in the MCS group $(17.8 \%$ vs $4.8 \% ; P<.01)$. Patients bridged with a ventricular assist device or total artificial heart had midterm outcomes comparable to those of the non-MCS group.

Sanchez and colleagues ${ }^{2}$ have provided the MCS community with a valuable assessment of MCS support for cardiac retransplantation that demonstrates feasibility and reasonable long-term survival in light of the critical illness and complexity of issues with this group. There are a number of limitations in the report by Sanchez and colleagues. ${ }^{2}$ The study cohorts were small when comparing subgroups of

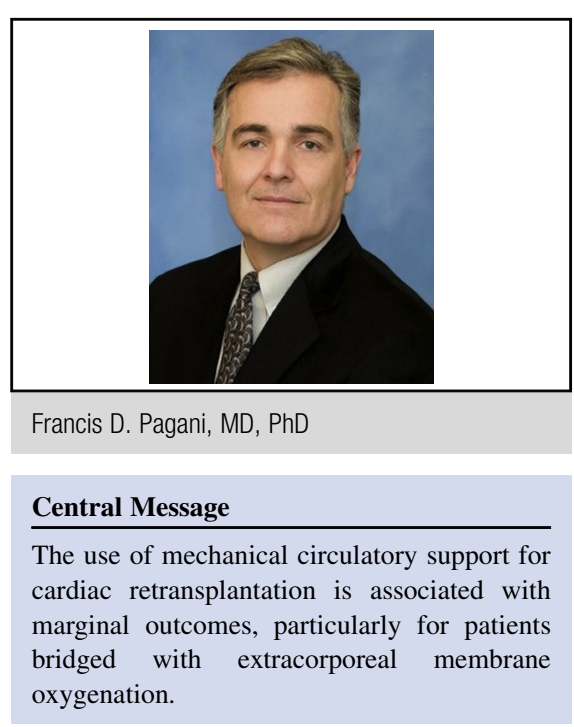

See Article page 171

patients stratified by device type and when assessing longterm outcomes, particularly when comparing outcomes with those of patients undergoing retransplantation without MCS. The numbers of patients alive at longer follow-up in the MCS group were exceedingly small: 18 patients at 4 years and only 9 patients at 6 years for all MCS and only 14 and 7 patients, respectively, for the subgroup receiving ventricular assist device or total artificial heart support. Inferences as to optimal device or assessment of outcomes are thus very limited. A second important limitation of the study is that the denominator of all patients receiving MCS for retransplantation indication is unknown, and only patients thought to be reasonable candidates and listed for transplantation were available for analysis in the United Network for Organ Sharing database. The number of patients receiving MCS for cardiac retransplantation but ultimately not relisted because of early death or complications that arose early after MCS use is thus unknown. The outcomes from this report are therefore potentially biased and may represent an overwhelmingly favorable outcome of MCS for this indication.

The results of using MCS as a bridge to cardiac retransplantation reported by Sanchez and colleagues ${ }^{2}$ are not entirely unexpected. What effect the new changes in the heart allocation system will have on provider biases in feasibility and the decision to proceed with MCS for cardiac retransplantation are unknown, but rigorous follow-up will 
be needed to determine the effect on overall use and outcomes of MCS for this indication.

\section{References}

1. Lund LH, Khush KK, Cherikh WS, Goldfarb S, Kucheryavaya AY, Levvey BJ, et al; International Society for Heart and Lung Transplanta- tion. The Registry of the International Society for Heart and Lung Transplantation: thirty-fourth adult heart transplantation report-2017; focus theme: allograft ischemic time. J Heart Lung Transplant. 2017;36: 1037-46.

2. Sanchez JE, Takayama H, Ando M, Han J, Kurlansky P, Garan AR, et al. Outcomes of bridge to cardiac retransplantation in the contemporary mechanical circulatory support era. J Thorac Cardiovasc Surg. 2019;158:171-81.e1. 